\title{
A Constituiçấo do Público-Alvo na Política de Educaçâo Especial Brasileira: Movimentos E Disputas no InTERior do Estado INTEgraL ${ }^{1}$ The Constitution of the Target Population in the Brazilian Special Education Policy: Movements and Disputes Within the Integral State
}

\author{
Rosalba Maria Cardoso GARCIA² \\ Liliam Guimarães de BARCELOS ${ }^{3}$
}

\begin{abstract}
RESUMO: Este trabalho objetiva evidenciar os movimentos políticos e sua participação na constituiçáo do público-alvo das políticas de Educaçáo Especial no Brasil. Com os pressupostos do materialismo histórico dialético, compreendem-se a política como relação de forças. Analisaram-se fontes documentais que demarcaram mudanças relativas ao público-alvo, bem como literatura acadêmica. Apoiadas no conceito de Estado Integral, verificam-se que as instituiçôes privadas e assistenciais, como aparelhos privados, marcaram posição nas definiçôes das políticas de Educação Especial. Ressaltam-se a criação de dois tipos de movimento: de e para pessoas que demandam políticas públicas de Educação Especial - o primeiro representado por instituições privadas e assistenciais; e o segundo, formado pelos próprios sujeitos com condiçóes específicas, cada qual com demandas particulares. Constataram-se que a participação dos movimentos na constituição do público-alvo da Educação Especial acontece em níveis diferentes, com os movimentos de e para pessoas com deficiências adotando a estratégia de participação em cargos públicos na esfera do aparelho de Estado para que seus interesses sejam incorporados às políticas educacionais, evidenciando a articulaçáo das organizaçóes da sociedade civil como elemento constituidor do Estado Integral. Por fim, destacam-se a forma de atuação política fragmentária dos movimentos com vistas a demandas específicas.
\end{abstract}

PALAVRAS-CHAVE: Política de Educação Especial. Público-alvo. Estado Integral. Sociedade civil. Movimentos políticos.

\begin{abstract}
This paper aims to highlight the political movements and their participation in the constitution of the target population of the policies of Special Education in Brazil. With the assumptions of dialectical historical materialism, we understand the policy as a relation of forces. Thus, we analyzed documentary sources that marked changes related to the target population, as well as academic literature. Supported by the concept of Integral State, we verified that private and welfare institutions, as private apparatus, marked their position in the definitions of Special Education policies. We emphasize the creation of two types of movement: of and for people who demand Special Education public policies - the first represented by private and welfare institutions; and the second, formed by the subjects themselves with specific conditions, each with particular demands. We noted that the participation of movements in the constitution of the target population of Special Education happens at different levels, with movements of and for people with disabilities adopting the strategy of participation in public positions in the State apparatus so that their interests are incorporated into education policies, highlighting the articulation of Civil Society organizations as a constituent element of the Integral State. Finally, we highlight the form of fragmentary political action of the movements with a view to specific demands.
\end{abstract}

KEYWORDS: Special Education policy. Target population. Integral State. Civil society. Political movements.

\section{INTRODUÇÃo}

No presente artigo, objetivamos evidenciar os movimentos políticos e sua participação na constituição do público-alvo da Educação Especial (PAEE) no Brasil, tomando como referência o conceito de Estado Integral (Gramsci, 1976). Para essa análise, examinamos como

\footnotetext{
${ }^{1}$ https://doi.org/10.1590/1980-54702021v27e0170

${ }^{2}$ Doutora em Educação. Centro de Ciências da Educação. Departamento de Estudos Especializados em Educação. Campus Universitário Trindade. Florianópolis/Santa Catarina/Brasil. E-mail: rosalba.garcia@ufsc.br. ORCID:

https://orcid.org/0000-0003-3260-6982

${ }^{3}$ Mestre em Educação. Fundação Catarinense de Educação Especial (FCEE). São José/Santa Catarina/Brasil. E-mail: liliambarcelos84@gmail.com. ORCID: https://orcid.org/0000-0003-1154-5084
} 
corpus central três documentos representativos das políticas de Educação Especial de âmbito nacional: 1) Política Nacional de Educação Especial (1994), que teve como objetivo normatizar e orientar a educação de estudantes com deficiências, condutas típicas e altas habilidades; 2) Resolução CNE/CEB no 2, de 11 de setembro de 2001, que instituiu Diretrizes Nacionais para a educação de "alunos que apresentem necessidades educacionais especiais"; e Política Nacional de Educação Especial na Perspectiva da Educação Inclusiva (2008), que tem como objetivo garantir a inclusão dos "alunos com deficiências, transtornos globais do desenvolvimento e altas habilidades/superdotação” (p. 8) nas escolas regulares. Tais documentos foram selecionados por apresentarem alteraçóes na compreensão sobre o PAEE.

Confrontamos os documentos selecionados com outros, tomando como base os pressupostos teóricos e metodológicos do materialismo histórico e dialético, a fim de captar o "movimento que constituiu determinada política como realidade objetiva" (Shiroma \& Evangelista, 2018, p. 22), considerando que a política não pode ser pensada descolada da história e da economia. Entendemos que os documentos da área "expressam, não apenas diretrizes para a educação, mas articulam interesses, projetam políticas, produzem intervenções sociais” (Evangelista, 2012, p. 56).

A pesquisa de produçóes acadêmicas foi desenvolvida nas bases de dados: Scientific Electronic Library Online (SciELO), Portal de Periódicos da Coordenação de Aperfeiçoamento de Pessoal de Nível Superior/Ministério da Educação (CAPES/MEC), Biblioteca Digital Brasileira de Teses e Dissertações (BDTD), Anais da Reunião Anual da Associação Nacional de Pós-Graduação e Pesquisa em Educação (ANPEd), Catálogo de Teses e Dissertações (CAPES), Anais do VII Congresso Brasileiro de Educação Especial e Revista Educação Especial da Universidade Federal de Santa Maria (UFSM). Utilizamos nas bases de dados selecionadas os descritores: educação especial; público-alvo; alunos; estudantes; educandos; necessidades especiais; e política educacional.

Evidenciamos que, a partir de 2008, o PAEE foi definido como estudantes com deficiências (mental, visual, auditiva, física e múltipla), com transtornos globais do desenvolvimento (TGD) e com altas habilidades/superdotação. A análise documental corroborou que, embora as terminologias utilizadas para referir determinados grupos de estudantes sofram alteraçóes no decorrer do tempo, alguns permanecem contemplados. É o caso dos estudantes com deficiências e com altas habilidades/superdotação. A categoria Transtornos Globais do Desenvolvimento (TGD), incorporada somente na Política de 2008, engloba os estudantes com autismo clássico, síndrome de Asperger, síndrome de Rett, transtorno desintegrativo da infância (psicoses) e transtornos invasivos sem outra especificação. Contudo, tais sujeitos foram contemplados, anteriormente, ainda que não discriminadamente, nas categorias "excepcionais" ${ }^{4}$, "educandos com problemas de conduta", e "portadores de condutas típicas". Ressaltamos que, em 2013, com a publicação da nova versão do Manual Diagnóstico e Estatístico de Transtornos Mentais (DSM-V), todos os transtornos que compóem a categoria TGD foram absorvidos na categoria Transtornos do Espectro Autista (TEA) (Araújo \& Lotufo Neto, 2014).

\footnotetext{
${ }^{4}$ Lei no 4.024, de 20 de dezembro de 1961.

${ }^{5}$ Decreto no 72.425, de 3 de julho de 1973. "Cria o Centro Nacional de Educação Especial (CENESP), e dá outras providências".

${ }^{6}$ Política Nacional de Educação Especial (1994).
} 
Empreendemos análise sobre a participação dos movimentos políticos relacionados a cada um dos grupos que constituem o PAEE, com o intuito de identificar como se articularam para terem seus interesses incorporados às políticas para a Educação Especial. Com base na perspectiva gramsciana, consideramos necessário explicitar dois conceitos densamente relacionados: política e Estado. Para Gramsci (1976), a política está definida como "forças sociais em luta”, mediante grupos que buscam articular seus interesses para que sejam reconhecidos como vontades coletivas. A partir dessa compreensáo, apresentamos a dinâmica de diferentes grupos que, historicamente, disputaram a formulação da política nacional de Educação Especial e a definição de seu público-alvo. Asseveramos que tais grupos constituem movimentos políticos mais ou menos conscientes das lutas que travam e que tanto se associam entre si como disputam posiçóes.

Já a compreensão acerca do Estado, na concepção gramsciana, remete a "todo o complexo de atividades práticas e teóricas com as quais a classe dirigente justifica e mantém não só o seu domínio, mas consegue obter o consentimento ativo dos governados" (Gramsci, 1976, p. 87). Portanto, na tradição do pensamento marxista, o autor entende o Estado burguês como expressão da luta de classes, de forma a articular o domínio do capital sobre o trabalho. Todavia, Gramsci complementa, em suas análises, que o Estado não atua somente na dominação, mas também atua fortemente na produção de consentimentos dos subalternos.

Mais do que a face estrita, Gramsci (1976) propóe-se a compreender o Estado em seu sentido integral, quando afirma que "por 'Estado' deve-se entender, além do aparelho governamental, também o aparelho 'privado' de 'hegemonia' ou sociedade civil” (p. 147). O autor coloca atenção nos processos ampliados de atuação da sociedade civil, que opera pela construção da hegemonia e sua conjunção com a sociedade política (Montaño \& Duriguetto, 2011). $\mathrm{Na}$ letra do pensador sardo, o "Estado = sociedade política + sociedade civil, isto é, hegemonia revestida de coerção" (Gramsci, 1976, p. 149). Trata-se, portanto, de equilíbrios instáveis que dinamizam a articulação Estado e política.

Consideramos que os movimentos políticos relacionados aos grupos de sujeitos que compóem o PAEE estão socialmente representados mediante aparelhos privados, bem como, por seus intelectuais, os quais se vinculam, em maior ou menor proporção, à sociedade política, de forma a ter seus interesses incorporados às políticas públicas para a Educação Especial.

Gramsci (1976) cunhou a expressão aparelhos privados de hegemonia para referir as organizaçóes da sociedade civil que tem como principal função "construir o consenso das grandes massas pouco organizadas, de modo a obter sua adesão aos projetos articulados pelos grupos dominantes" (Mendonça, 2014, p. 35). Portanto, ainda que as pautas de grupos que se aglutinam em torno das causas dos sujeitos que demandam políticas públicas de Educação Especial não estejam conscientemente vinculadas aos interesses da classe dominante, acabam por fortalecê-la. Cumpre lembrar que as políticas públicas de Educação Especial têm sua gênese e desenvolvimento dinamizados pelo avanço da hegemonia liberal no país (Kassar, 1998) e, mais recentemente, aos propósitos de um projeto educacional do capital, disseminado mundialmente pelos organismos multilaterais (Garcia, 2017).

A partir das premissas apresentadas, observamos como características comuns aos movimentos políticos que se organizaram em torno das pautas dos grupos que constituem o PAEE no Brasil: 1) São associações privadas da sociedade civil; 2) Participam de mobiliza- 
ções pela defesa dos direitos de um grupo específico, não assumindo pautas universalistas; 3) Constituem federaçóes estaduais e nacionais como estratégia de capilaridade e representação política e, em alguns, casos, participam de organizaçóes internacionais; 4) Buscam assento nos conselhos estaduais e federais que tratam das questóes ligadas aos direitos de seus representados, atuando por dentro das instâncias da sociedade política; 5) Constituem movimentos de ou para sujeitos que demandam políticas públicas de Educação Especial.

\section{A constituição da Educaçáo Especial e de SEU Público-alvo}

Identificamos no ensino emendativo, a partir da década de 1930, uma iniciativa do Estado para o atendimento educacional dos "anormais", pautado em sua adaptação ao meio social, de forma que pudessem se converter "em cidadãos úteis e capazes", barateando os custos com seu atendimento (Decreto no 24.794, de 14 de julho de 1934) ${ }^{7}$. Essa forma de ensino foi ofertada por instituiçóes filantrópicas, dentre as quais, a Sociedade Pestalozzi, que atuou de forma intensa na formulação de políticas para a Educação Especial brasileira e, especialmente, em relação à definiçãao de seu público-alvo.

Entretanto, desde o período imperial, estão registrados os atendimentos de pessoas com deficiência visual no Imperial Instituto dos Meninos Cegos - atual Instituto Benjamim Constant (IBC) - e de pessoas com deficiência auditiva, no Instituto Imperial para SurdosMudos, - hoje, Instituto Nacional de Educação de Surdos (INES). Tais instituiçóes, criadas a partir da mobilização de "vultos" da história brasileira, sempre estiveram ligados ao poder central, o que, na análise de Jannuzzi (2012), possivelmente favoreceu a inclusão dos estudantes com deficiência visual e auditiva como público-alvo das políticas de Educação Especial.

Outro tipo de movimento foi observado por Jannuzzi (2012, p. 97), a partir da década de 1950, quando os "próprios deficientes começaram a organizar-se, procurando participar de discussóes em torno de seus problemas". Identificamos a criação, em 1954, do Conselho Brasileiro para o Bem-Estar dos Cegos (CBEC), fundado por iniciativa de Dorina Nowill e do diretor do IBC, Rogério Vieira, além de algumas associaçóes de pessoas com deficiências físicas que, inicialmente, buscavam viabilizar recursos para a sobrevivência de seus afiliados. Posteriormente, com a popularização do esporte adaptado, após a Segunda Guerra Mundial, foram criadas organizaçóes voltadas à prática de esporte, culminando na fundação de clubes esportivos (Lanna Junior, 2010). A partir daí, evidenciamos o crescimento da atuação do setor privado no atendimento às pessoas com deficiência, "tanto o de caráter filantrópico quanto o pago [...], diferenciando, provavelmente, a eficiência dos resultados" (Jannuzzi, 2012, p. 87).

Sob a influência das instituiçóes privado-filantrópicas e das associaçóes de pessoas com deficiência que haviam se constituído no âmbito da sociedade civil, foram lançadas, em 1957, a Campanha de Educação do Surdo Brasileiro (CESB) - proposta pela então diretora do INES, Ana Rímoli de Faria Dória - e a Campanha Nacional de Educação e Reabilitação dos Deficitários Visuais (CNERDV), em 1958 - por intermédio de José de Espíndola Veiga, do IBC. Esta última teve Dorina Norwill como primeira diretora e, em 1960, passou a denominar-se Campanha Nacional de Educação dos Cegos (CNEC), sendo subordinada diretamente

\footnotetext{
7 "Cria, no Ministério da Educação e Saúde Pública, sem aumento de despesa, a Inspetoria Geral do Ensino Emendativo, dispóe sobre o Ensino do Canto Orfeônico, e dá outras providências” (Decreto no 24.794, 1934).
} 
ao Ministério da Educação e Cultura (Jannuzzi, 2012). Naquele ano, foi instituída, também, a Campanha Nacional de Educação e Reabilitação dos Deficientes Mentais (CADEME), que contou com Helena Antipoff como integrante da comissão diretora. Tais Campanhas possibilitaram o financiamento com recursos públicos de entidades privadas sem fins lucrativos para a oferta de atendimento aos alunos com deficiência mental/intelectual ${ }^{8}$, visual e auditiva. Jannuzzi (2012) aponta o aumento considerável no número de instituiçóes para atendimento de pessoas com deficiência mental/intelectual, principalmente a partir da década de 1960, fruto do incentivo financeiro possibilitado pela CADEME. As campanhas permitiram não somente a expansão do atendimento educacional para esses grupos como também a capilaridade do debate político em torno das pautas desses grupos no país.

Dentre as instituiçóes criadas para atender a pessoas com deficiência mental/intelectual, as Associaçóes de Pais e Amigos dos Excepcionais (APAEs), surgidas a partir dos anos de 1950, destacaram-se por sua rápida expansão e pela organização da Federação Nacional das Associaçóes de Pais e Amigos dos Excepcionais (FENAPAES) que, historicamente, se articulou de forma intensa com o poder público, disputando o espaço de atendimento e recursos públicos destinados à Educação Especial (Lehmkuhl, 2018; Silva, 2017).

Em 1961, foi promulgada a primeira Lei de Diretrizes e Bases da Educação Nacional (LDBEN) - Lei no 4.024/1961 -, que dispôs, no Título X, sobre a educação dos "excepcionais" como parte da educação geral e assegurou à "iniciativa privada considerada eficiente pelos conselhos estaduais de educação" o recebimento de "bolsas de estudo, empréstimos e subvençóes".

Rafante e Lopes (2009) esclarecem que o termo "excepcionais" foi empregado por Helena Antipoff para nomear crianças e adolescentes que "se desviavam da norma, estando acima ou abaixo da média, em relação às suas características mentais, físicas ou sociais, de forma a criar um problema relacionado à sua educação" (p. 239). Para Rafante (2011), a mobilização realizada pelas Sociedades Pestalozzi foi fundamental para a inclusão da Educação Especial na LDBEN de 1961. Tal fato evidencia a influência desse aparelho privado da sociedade civil na definição do PAEE e na apropriação dos recursos públicos para o setor.

Já a Lei no 5.692, de 11 de agosto de 1971, que ampliou o ensino obrigatório para a faixa etária de 7 a 14 anos, definiu que os alunos que apresentassem "deficiências físicas ou mentais, os que se encontrem em atraso considerável quanto à idade regular de matrícula e os superdotados" deveriam "receber tratamento especial, de acordo com as normas fixadas pelos competentes Conselhos de Educação". Naquele mesmo ano, o MEC havia recomendado a extinção das Campanhas Nacionais com o objetivo de implantar um "programa integrado de assistência a todas as categorias de 'excepcionais" (Lemos, 1981, p. 72). No ano seguinte, foi instituído pelo Governo Federal, no I Plano Setorial de Educação e Cultura 1972-1974, o Projeto Prioritário no 35, que definia a Educação Especial como uma das prioridades educacionais. Esse projeto foi elaborado por membros do Grupo Tarefa de Educação Especial (GTEE), com a colaboração de Helena Antipoff e outros envolvidos com as Sociedades Pestalozzi e com a APAE, além de técnicos norte-americanos patrocinados pela United States Agency International

\footnotetext{
${ }^{8}$ Neste texto, consideramos os termos deficiência mental e intelectual como sinônimos, tendo em vista que, na materialidade da organização escolar, esses termos abrangem o mesmo grupo de alunos, conforme constatamos em análise sobre os cadernos de preenchimento do Censo Escolar dos anos que compreendem o período selecionado para nossa análise. No caso de citação direta, de reprodução de texto de documentos oficiais e de nomes de entidades, mantivemos o termo conforme escrita original.
} 
for Development (USAID) e um representante da Organização das Nações Unidas (ONU) (Rafante, 2015, p. 9).

Para implantação desse Projeto foi criado, por meio do Decreto no 72.425 , de 3 de julho de 1973, o Centro Nacional de Educação Especial (CENESP), que teve como objetivo "promover em todo o território nacional, a expansão e melhoria do atendimento aos excepcionais". Interessante observar que, no Decreto de criação do CENESP, ao mesmo tempo que é utilizado o termo "excepcionais", está determinado que esse órgão "atuará de forma a proporcionar oportunidades de educação, [...] para os deficientes da visão, audição, mentais, físicos, educandos com problemas de conduta para os que possuam deficiências múltiplas e os superdotados, visando sua participação progressiva na comunidade". Assim sendo, notamos semelhança na definição dos grupos que compóem a categoria "excepcionais" com aqueles que constituem o PAEE em documentos elaborados posteriormente, inclusive na Política de 2008.

Verificamos, com isso, que os sujeitos que compuseram o PAEE no momento da institucionalização desse campo da educação no Brasil, e que permaneceram contemplados como público-alvo nos documentos da política de Educação Especial posteriores, já vinham sendo atendidos por instituiçóes vinculadas ao poder público, como os atuais INES e o IBC e instituições privadas da sociedade civil, como as Sociedade Pestalozzi e as APAEs, que exerceram grande influência na formulação de políticas públicas para os sujeitos os quais representavam. Tais instituições representam o que Lanna Junior (2010) denominou como movimentos políticos para pessoas com deficiência, os quais foram contrapostos pelos movimentos políticos de pessoas com deficiência, surgidos no final da década de 1970. Esses movimentos, por sua vez, congregavam novas associaçóes, formadas pelas próprias pessoas com deficiências, que reivindicavam, principalmente, o fim da tutela, representada pelo modelo caritativo de deficiência (Lanna Junior, 2010).

Nessa dinâmica, alguns grupos mais organizados no âmbito da sociedade civil - principalmente os grupos de pessoas com deficiência física e com deficiências visuais - articularam-se e criaram, em 1979, a Coalizão Pró-Federação Nacional de Entidades de Pessoas Deficientes, que buscava "elaborar uma agenda única de reivindicaçóes e estratégias de luta, bem como fundar a Federação Nacional de Entidades de Pessoas Deficientes” (Lanna Junior, 2010, p. 37). A organização da Coalização culminou na realização de três Encontros Nacionais de Entidades de Pessoas Deficientes (1980 a 1983), nos quais se buscou unificar as pautas dos diferentes grupos de pessoas com deficiências (Lanna Junior, 2010). Contudo, as disputas dentro do próprio movimento impediram a criação de uma federação única, gerando várias federações nacionais por tipo de deficiência, como a Federação Nacional de Educação e Integração dos Surdos (FENEIS), a Federação Brasileira de Entidades de e para Cegos (FEBEC) e a Organização Nacional de Entidades de Pessoas com Deficiência Física (ONEDEF), todas criadas na década de 1980.

Na análise de Silva (2017), a separação por área de deficiência acabou por desmobilizar a luta nacional do movimento das pessoas com deficiência. Consideramos que esse pode ter sido um fator importante para consolidar esses movimentos com um caráter fragmentário, distanciando-os dos debates mais articulados em torno das pautas da classe trabalhadora.

Verificamos que a fragmentação do Movimento Político das Pessoas com Deficiência por áreas favoreceu o surgimento dos novos movimentos sociais que defendem grupos espe- 
cíficos de pessoas com deficiência, os quais passaram a disputar, cada qual à sua maneira, o atendimento de interesses privados na formulação das políticas públicas, alcançando maior ou menor penetração no aparelho de Estado.

\section{MoVimentos POLíticos E EdUCAÇÃo ESPECIAL: DISPUTAS NA FORMULAÇÃO DE POLÍTICAS PÚBLICAS}

Passamos a reportar uma análise dos movimentos políticos em sua relação com as políticas de Educação Especial no Brasil. Para tanto, vamos tratar dos grupos que estão representados como PAEE na fase atual: pessoas com deficiência, altas habilidades/superdotação e transtornos do espectro do autismo (TEA). Levamos em conta a constituição de associaçóes da sociedade civil em torno dos grupos referidos, aqui compreendidos como aparelhos privados, bem como de lideranças reconhecidas à frente de tais associaçóes, apreendidos como intelectuais.

A população com deficiência visual foi atendida, a partir do período imperial, pelo atual Instituto Benjamin Constant, instituição pública de pequeno alcance numérico, se considerarmos a área territorial do país e sua localização no Rio de Janeiro. Nas décadas de 1930 e 1940, teve início uma expansão privado-assistencial de atenção a esse público. Dentre essas instituiçôes, a Fundação para o Livro do Cego no Brasil - criada por iniciativa de Dorina Nowill - destaca-se não só pela ampliação da produção de livros em Braille no país, como também pelos atendimentos reabilitatórios, formação de professores e técnicos para atuar na área da deficiência visual e, principalmente, por sua participação decisiva na política de atendimento às pessoas com deficiência visual no Brasil (Bueno, 2011).

Identificamos que a Fundação para o Livro do Cego no Brasil, como instituição representante dos interesses das pessoas com deficiência visual, embora também tenha se articulado pela via das relaçóes público-privadas, apresentava como especificidade a reivindicação do atendimento educacional dos alunos com deficiência nas escolas regulares. Dentre os intelectuais representantes desse grupo, destacamos Dorina Nowill, com forte atuação nos debates realizados no Congresso Nacional e articulação internacional, mediante sua participação na criação da União Latino-Americana de Cegos (ULAC) (Nowill, 2009). Destacamos, também, Adilson Ventura, que, em 2002, assumiu a presidência do Conselho Nacional dos Direitos das Pessoas com Deficiência (CONADE). Isso demonstra a presença do movimento de pessoas com deficiência visual nas deliberaçóes sobre as políticas do setor, por dentro do aparelho do Estado, fato também evidenciado pela participação da FEBEC, a partir de 1986, no Conselho Consultivo da Coordenadoria Nacional para Integração da Pessoa Portadora de Deficiência (CORDE) (Lanna Junior, 2010).

Em uma tentativa de unificação entre a FEBEC e o CBEC, foi fundada, em 1988, a União Brasileira de Cegos (UBC). Contudo, essa experiência de unificação não foi bem sucedida e, em 2008, foi criada a Organização Nacional de Cegos do Brasil (ONCB) (Lanna Junior, 2010), instituição que tem representado as organizaçôes nacionais de e para pessoas com deficiência visual no CONADE?

${ }^{9}$ Ver https://www.mdh.gov.br/informacao-ao-cidadao/participacao-social/orgaos-colegiados/conade/composicao 
Para a análise sobre como se articularam os grupos de defesa das pessoas com deficiência visual a partir da década de 1990, foram poucos os registros que puderam nos auxiliar. Identificamos, contudo, a participação de pessoas ligadas à área da deficiência visual na formulação da Política Nacional de Educação Especial (1994) e na Resolução CNE/CEB no $2 / 2001^{10}$, além da participação de Adilson Ventura como presidente do CONADE, entre os anos de 2002 e 2006.

Sobre as pessoas com deficiência auditiva, identificamos que, a partir das deliberações do Congresso de Milão ${ }^{11}$, o novo regimento do Instituto Nacional de Surdos-Mudos (INSM), instituído pelo Decreto no 9.198, de 12 de dezembro de 1911, definiu a adoção do "método oral puro" em todas as disciplinas. Tal fato oficializou a opção do Brasil pelo oralismo como método de ensino da pessoa surda, em detrimento ao uso da Língua de Sinais (Bentes \& Hayashi, 2016). Com a mudança de direção do INSM em 1951, Ana Rímoli de Faria Dória criou o Curso Normal de Formação de Professores para Surdos, o qual passou a formar professoras de todo o Brasil para atuarem com crianças com deficiência auditiva. As açóes da nova diretora contribuíram para que, em 1957, fosse lançada a Campanha para a Educação do Surdo Brasileiro (CNESB), desenvolvida até 1961, acarretando a criação de inúmeras escolas de surdos por todo o país (Bentes \& Hayashi, 2016). Com isso, a expansão da proposta de atendimento educacional para alunos surdos, por meio das Campanhas de Surdos e da formação de professores no INES, propagou o método da oralização como foco do ensino de surdos no Brasil. Conforme Lanna Junior (2010), foi nesse contexto de ênfase na oralidade que surgiram os movimentos surdos como resistência às práticas “ouvintistas” e à proibição da Língua de Sinais.

Tais movimentos têm expressão quando o grupo de profissionais ouvintes, atuantes na área da deficiência auditiva e que criaram a Federação Nacional de Educação e Integração do Deficiente Auditivo (FENEIDA) no Rio de Janeiro em 1978, foi confrontado em processo eleitoral, em 1987, por uma chapa presidida pela surda Ana Regina Campello. Com a chapa eleita e a posse da nova diretoria, foi reestruturado o estatuto da instituição, passando a denominá-la Federação Nacional de Educação e Integração dos Surdos (FENEIS). Tal mudança indica uma perspectiva que desloca o foco central da deficiência para uma identidade cultural (Lanna Junior, 2010), como conteúdo de uma disputa política pela direção do movimento.

Identificamos também que, no período de elaboração da Constituição Federal, o movimento de surdos, articulado pela FENEIS, buscou que fosse reconhecida a Língua de Sinais, como língua oficial dos surdos, em uma associação entre língua e cultura: a cultura surda. Após derrota na Constituinte, a referida federação elaborou, em 1990, um documento intitulado As comunidades surdas reivindicam os seus direitos linguisticos (FENEIS, 1993), no

\footnotetext{
${ }^{10} \mathrm{Na}$ formulação da Política Nacional de Educação Especial (1994), identificamos a participaçáo de representantes do IBC e da FEBEC, enquanto o Parecer CNE/CEB no 17/2001, que antecede a Resolução CNE/CEB no 2/2001, indica a participação de Carmelino Vieira, então Diretor do IBC e Roseli Cecília Rocha de Carvalho Baumel, professora da Faculdade de Educaçấo da Universidade de São Paulo (USP), pesquisadora da área da deficiência visual.

${ }^{11}$ O II Congresso Internacional sobre a Instrução de Surdos aconteceu em 1880, em Milão, na Itália. De acordo com Lacerda (1998, p. 6), a organização desse evento partiu de uma maioria de professores oralistas "com o firme propósito de dar força de lei às suas proposiçóes no que dizia respeito à surdez e à educação de surdos”. Ao final, foi realizada uma votação, na qual os professores surdos, em minoria, foram derrotados pela maioria de professores ouvintes, sendo aprovado o método oral como o melhor para o ensino de alunos surdos, em detrimento da Língua de Sinais (Bentes \& Hayashi, 2016).
} 
qual defende a tese de que as línguas de sinais são línguas naturais do povo surdo que, nessa perspectiva, constituem uma minoria linguística e cultural, devendo ser reconhecidos pela sociedade e pelo Estado. Esse documento instituiu, também, o uso do termo "Língua Brasileira de Sinais" (LIBRAS) para referir-se à linguagem de sinais utilizada pelos surdos brasileiros (Brito, 2016, p. 767).

Vemos, nessa reconfiguração do movimento de surdos, uma reformulação de suas pautas pelo reconhecimento da Língua de Sinais e da cultura surda como específica do povo surdo. Tais bandeiras destoam, em todos os aspectos, dos objetivos perseguidos pelos demais grupos de pessoas com deficiência, o que nos permite compreender o movimento político de surdos como um movimento muito específico, em relação aos movimentos sociais de pessoas com deficiência. O fortalecimento do movimento de surdos impactou também o INES, que passou por alteraçóes. Em 1993, a LIBRAS recebeu o status de língua de ensino e a língua portuguesa foi considerada como segunda língua. Nessa dinâmica, houve a contratação de professores que passaram a ministrar as aulas utilizando LIBRAS, ao mesmo tempo que o currículo do INES foi alterado para ofertar as disciplinas ensinadas nas escolas regulares (Bentes, 2010).

Em decorrência das açóes do movimento surdo, foi promulgada a Lei no 10.436 , de 24 de abril de 2002, que reconheceu a LIBRAS como um meio "legal de comunicação e expressão [...] oriundos de comunidades de pessoas surdas do Brasil". Em 2005, o Decreto $n^{\circ} 5.626$, de 22 de dezembro de 2005, regulamentou a Lei ${ }^{\circ} 10.436 / 2002$, passando a conceituar como "pessoa surda aquela que, por ter perda auditiva, compreende e interage com o mundo por meio de experiências visuais, manifestando sua cultura principalmente pelo uso da Língua Brasileira de Sinais - LIBRAS”. A partir da promulgação da legislação que reconheceu a LIBRAS como língua oficial, o INES adequou-se às determinaçóes legais. Em 2006, foi criado, no INES, o Instituto Superior Bilíngue de Educação com licenciatura em pedagogia, que oferece formação superior em Português/Língua Brasileira de Sinais para "surdos" e "ouvintes" (Bentes \& Hayashi, 2016, p. 869). Esse fato denota que, embora o INES tenha influenciado, por muito tempo, as determinaçóes sobre os métodos de ensino de pessoas com deficiência auditiva, pregando a oralização e a proibição da língua de sinais, com a ascensão do movimento político de surdos, que defende a LIBRAS, esse instituto tornou-se uma instância executora da política nessa nova configuração.

Nos últimos anos, acompanhamos o avanço das lutas travadas pelo movimento surdo pela garantia da implementação de escolas bilíngues, dentre as quais registramos a promulgação da Lei Brasileira de Inclusão da Pessoa com Deficiência (Lei no 13.146, de 6 de julho de 2015), que prevê "oferta de educação bilíngue, em LIBRAS como primeira língua e na modalidade escrita da língua portuguesa como segunda língua, em escolas e classes bilíngues e em escolas inclusivas". A partir de 2018, registramos um aprofundamento desse debate com vistas à "atualização" da Política de 2008, cuja proposição está intitulada como Política Nacional de Educação Especial: equitativa, inclusiva e ao longo da vida (2018). Nesse documento, está prevista a instituição de escolas bilíngues e classes bilíngues com serviços e recursos especializados para atendimento aos alunos surdos. Já no governo Bolsonaro, o Decreto no 9.665, de 2 de janeiro de 2019, instituiu esse direcionamento nas políticas educacionais ao criar a Diretoria de Políticas de Educação Bilíngue de Surdos. 
Identificamos, assim, que o movimento de pessoas surdas ganhou força ao longo da história, principalmente por meio de estratégia de publicização de suas demandas pela mídia, manifestaçóes e eventos culturais, além da ampliação do debate sobre o discurso linguístico-cultural da surdez também no meio acadêmico.

Em relação aos estudantes com deficiência mental/intelectual, constatamos que a Sociedade Pestalozzi atuou de forma pioneira no atendimento educacional a esse grupo, com intensa participação na formulação de políticas para a Educação Especial brasileira e, especialmente, em relação à definição de seu público-alvo.

A partir da criação da CADEME, o número de instituições de ensino para alunos com deficiência mental/intelectual aumentou exponencialmente. Dentre essas instituiçóes, estão as APAES, que se multiplicaram rapidamente pelo Brasil, o que resultou na criação de uma federação nacional, a FENAPAES, instituição hegemônica na área da deficiência mental/ intelectual até os dias de hoje (Silva, 2017). Uma das estratégias marcantes da FENAPAES, identificadas em nosso estudo, é a candidatura de alguns de seus membros para cargos públicos no Poder Executivo e Legislativo, nos âmbitos federal, estadual e municipal, o que possibilita sua atuação no aparelho de Estado.

No que tange às pessoas com deficiência física, nossa busca por dados acerca das articulaçóes políticas em prol de sua educação indicou a pouca produção acadêmica que analisa como esses grupos participaram da formulação de políticas para a Educação Especial no Brasil. Contudo, a partir de trabalhos que descreveram o Movimento Político das Pessoas com Deficiência, pudemos elaborar alguns apontamentos sobre as disputas políticas no campo da educação de pessoas com deficiência física.

Conforme Cabral Filho e Ferreira (2013), a iniciativa de articulação política das pessoas com deficiência, que resultou na formação da Coalizão Pró-Federação Nacional de Entidades de Pessoas Deficientes, em 1979, partiu, principalmente, de entidades e pessoas ligadas aos interesses das pessoas com deficiência física, a partir de necessidades expressas pelo grupo tais como rampa, atividade de lazer, reabilitação, integração na sociedade e no trabalho, acesso aos transportes. Constatamos, também, a forte participação das pessoas com deficiência física durante os Encontros realizados pelo Movimento Político das Pessoas com Deficiência na década de 1980 (Lanna Junior, 2010).

Verificamos que, ao contrário de outros grupos que reivindicavam estratégias específicas para promover o ensino das pessoas com deficiência - tais como o Braille e a Línguas de Sinais -, as pessoas com deficiência física reivindicavam acessibilidade para sua integração na sociedade.

Evidenciamos que, durante a Assembleia Nacional Constituinte, a Organização Nacional de Entidades de Pessoas com Deficiência Física (ONEDEF) foi representante do Movimento das Pessoas com Deficiência, participando ativamente das deliberaçóes para a formulação da Constituição Federal. Segundo Messias Tavares, representante da ONEDEF na ocasião, a escolha dessa entidade como representante de todo o movimento das pessoas com deficiência na Constituinte ocorreu por ser a mais bem organizada naquele momento (Lanna Junior, 2010). Também, nesse momento, a ONEDEF reivindicou a criação de um órgão que 
coordenasse todas as políticas públicas para as pessoas com deficiência que não só as políticas educacionais, o que contribuiu para a criação da CORDE. Ressaltamos que, embora tenhamos identificado a participação dessa entidade na formulação de políticas para as pessoas com deficiência, em nossos estudos não evidenciamos articulaçôes dessa instituição para a definiçãao de políticas para a educação, a não ser por uma participação, durante a Assembleia Constituinte, na qual defendia o direito das pessoas com deficiência estudarem nas escolas regulares, a exemplo dos movimentos pelos direitos dos estudantes com deficiência visual. Vemos que tal reivindicação vai na contramão dos interesses das entidades para pessoas com deficiência, como o movimento surdo, que reivindica a educação das pessoas surdas em escolas bilíngües e, também, a FENAPAES, que se constituiu como entidade hegemônica no campo da Educação Especial no Brasil, disputando o atendimento educacional das pessoas com deficiência nas instituições privado-assistenciais.

Importante destacarmos que parte dos sujeitos com deficiência física, por suas condiçóes específicas, tem sido atendida pelas APAEs, como entidades que, por promoverem o atendimento às pessoas com deficiência múltipla, atuam também no atendimento às pessoas identificadas com uma condição que articula deficiência física e mental/intelectual. Nesse sentido, compreendemos que as articulaçóes políticas dos grupos de defesa dos interesses das pessoas com deficiência física deram-se mais em relação às políticas de acessibilidade e de reabilitação do que em relação à educação. Quanto às disputas políticas que perpassam o campo da educação, a FENAPAES tem atuado como representação dos interesses das pessoas com deficiência física associada à deficiência mental/intelectual.

Quanto ao grupo de estudantes com altas habilidades/superdotação (AH/SD), constatamos que está contemplado pelas políticas de Educação Especial desde a primeira LDBEN (Lei no 4.024, 1961), a qual determinou o direito à educação aos excepcionais, preferencialmente no sistema regular de ensino.

Segundo relatos de Helena Antipoff (1992b como citado em Antipoff, 2010) em documentos da Sociedade Pestalozzi, os atendimentos prestados aos estudantes "bem dotados" tinham como objetivo fornecer aos jovens "uma educação física e moral para que a sua inteligência e seus dons possam servir utilmente à pátria” (p. 92). Esse registro evidencia que os atendimentos prestados a esses estudantes tinham como foco o ensino profissional, de modo que pudessem colaborar, pelas suas habilidades mais desenvolvidas, para o "desenvolvimento do país” (p. 93).

A Associação Milton Campos para o Desenvolvimento e Assistência de Vocações de Bem Dotados (ADAV), criada por Helena Antipoff em 1973, foi a primeira entidade voltada para os interesses de pessoas com superdotação no Brasil. De início, notamos que a nomenclatura utilizada para batizar a associação refere-se aos "bem dotados", e não aos superdotados, termo que havia sido oficializado nos documentos nacionais. Cecília Antipoff (2010) registra que Helena Antipoff tecia críticas ao termo "superdotado", "alegando se referir a algo raro e incomum" e propôs a utilização do termo "Bem Dotado" (p. 91) para se referir a esses indivíduos que se destacam quando comparado com seus pares, evitando, assim, estigmatizaçóes. Contudo, em seus registros em documentos da Sociedade Pestalozzi, a educadora russa utilizou, em alguns momentos, o termo "superdotado" para referir-se a esses estudantes. Inferimos 
que a educadora possa ter assumido o termo utilizado em documentos legais como forma de facilitar a atenção às reivindicaçóes para esse grupo. Outra iniciativa para atendimento de estudantes superdotados foi registrada em 1978, com a criação da Associação Brasileira dos Superdotados (ABSD).

Em 1993, Zenita Guenther fundou, em Lavras, Minas Gerais, o Centro para o Desenvolvimento do Potencial e Talento (CEDET), vinculado à Secretaria Municipal de Educação de Lavras, "com responsabilidade técnica da Associação de Pais e Amigos para Apoio ao Talento - ASPAT” (Guenther, 2013). Com base nos pressupostos desenvolvidos por Helena Antipoff, ao longo dos anos, o CEDET foi ampliando sua atuação para outros municípios do país, passando a atuar nos estados de Espírito Santo, São Paulo e Tocantins, além de Minas Gerais (Guenther, 2007). Os termos "boa dotação" e "bem dotado" foram utilizados por Guenther, em seus estudos, por influência de Antipoff, até a década de 2000, quando a pesquisadora considerou que "a raiz do problema náo estava no grau conceitual de dotação, mas na tradução do termo giftedness" (Guenther \& Rondini, 2012, p. 250). A partir de então, Guenther passou a utilizar o termo dotação, o qual difundiu largamente em seus estudos e no trabalho desenvolvido no CEDET.

Em 2002, especialistas envolvidos com a área das AH/SD fundaram o Conselho Brasileiro para Superdotação (COnBRASD). Segundo Perez (2012), "a questão da terminologia foi um dos temas que lideraram as discussóes. Considerando que o termo superdotação em si encerrava um conceito mais ou menos homogêneo [...]” (p. 55), chegou-se ao consenso de que o termo altas habilidades/superdotação era o mais adequado, de forma a contemplar as preferências da maioria dos pesquisadores presentes.

O fortalecimento de uma articulação nacional possivelmente influenciou para que, em 2005, a SEESP/MEC implementasse, em cada estado brasileiro e no Distrito Federal, os Núcleos de Atividades de Altas Habilidades/Superdotação (NAAH/S), em parceria com as secretarias estaduais de educação, com o objetivo de promover a identificação desses estudantes nas escolas, bem como disseminar conhecimentos sobre esse tema. Desde então, as publicaçóes oficiais têm assumido o termo altas habilidades/superdotação. Registramos que, a partir da criação dos NAAH/S, não só o atendimento mas também o debate político relacionado a esse grupo foi capilarizado no país.

Nossa busca por compreender a relação dos movimentos políticos ligados às pessoas com altas habilidades/superdotação, na constituição do PAEE, permitiram-nos constatar que esse grupo esteve contemplado em todos os documentos da política de Educaçáo Especial. Embora não tenhamos evidenciado disputas pela inserção desses sujeitos como PAEE, constatamos que há divergências entre os pesquisadores da área, principalmente em relação à nomenclatura mais adequada para referir esse grupo.

Por fim, apresentaremos os movimentos políticos relacionados às demandas das pessoas com autismo. Verificamos que, assim como os estudos que discorrem sobre o autismo, a organização do movimento político relacionado a esse grupo também ocorreu tardiamente, em relação aos demais grupos de sujeitos que constituem o PAEE. 
No Brasil, a partir da década de 1980, foram formadas associaçôes de pais que, embora tenham buscado apoio do setor público para atendimento às suas demandas, pouco participaram da definição de políticas públicas para os sujeitos diagnosticados com autismo. Duas entidades têm destaque em nossa análise: a Associação dos Amigos dos Autistas (AMA), que aparentemente se ocupou da articulação pelo atendimento e pela divulgação da causa e a Associação Brasileira de Autismo (ABRA), que participou das definições das políticas públicas.

Embora os movimentos ativistas formados pelas próprias pessoas com autismo tenham crescido nos últimos anos no país, é o ativismo das famílias que detém maior projeção e visibilidade (Rios, 2017), representando o movimento político para pessoas com autismo. A articulação desse movimento suscitou a criação da Lei no 12.764, de 27 de dezembro de 2012, que institui a Política Nacional de Proteção dos Direitos da Pessoa com Transtorno do Espectro Autista. O ponto principal a ser destacado nessa lei é a consideração de que, para todos os efeitos legais, a pessoa com TEA é uma pessoa com deficiência. Com isso, tais pessoas passaram a ser beneficiadas por todas as políticas para pessoas com deficiência já existentes. $\mathrm{Na}$ área da educação, contudo, observamos que essa determinação não acarretou mudanças, tendo em vista que a Política Nacional de Educação Especial na Perspectiva da Educação Inclusiva (2008) já previa atendimento educacional especializado para os alunos com TEA, então compondo a categoria TGD.

A partir da exposição aqui apresentada podemos, como efeito de síntese, apontar o caráter fragmentário do movimento político relacionado aos grupos de estudantes que compóem o PAEE, por meio da organização de aparelhos privados de hegemonia que se mobilizam em torno das pautas específicas de determinados grupos.

Historicamente, tais entidades da sociedade civil articularam-se, cada qual à sua maneira, no âmbito do Estado Integral, para incorporação de seus interesses às políticas públicas. A depender da forma de interpenetração na sociedade política, conquistaram maior ou menor reconhecimento de suas demandas.

\section{ConsideraçóEs finais}

Nossa análise evidenciou que os movimentos que disputam politicamente a definição do PAEE articulam-se como organizaçóes, associações, federaçôes, consistindo em aparelhos privados da sociedade civil. Tais organizaçóes sáo constituídas por sujeitos que, por exercerem uma liderança política e direcionarem tais movimentos, podem ser identificados como intelectuais (Gramsci, 1976).

Constatamos que os movimentos de e para estudantes que demandam políticas públicas de Educação Especial, ao adotarem como estratégia a participação em cargos públicos na esfera do aparelho de Estado, assumem uma atuação ativa para que seus interesses sejam incorporados às políticas educacionais. Com a criação de órgãos para a integração das pessoas com deficiência e defesa de seus direitos formais, como CORDE e CONADE, esses movimentos se articulam para compor o aparelho de Estado. Dessa forma atuam também como sociedade política. Constatamos nos movimentos políticos aqui referidos, portanto, a articulação das organizaçôes da sociedade civil como elemento constituidor do Estado Integral. 
Observamos, ainda, que tais movimentos políticos, ao disputarem a definição do PAEE, têm participado ativamente também nos debates sobre as concepçóes do trabalho educacional a ser desenvolvido nessa modalidade. Por fim, consideramos que a fragmentação dos grupos que disputam a política nacional de Educação Especial, organizados pelas condições específicas dos sujeitos, aprofunda a competitividade pelos recursos públicos em uma perspectiva de adaptação ao existente, ao mesmo tempo que enfraquece a aglutinação de forças visando lutas sociais anticapitalistas, as quais poderiam construir um horizonte emancipatório para as pessoas com deficiência.

\section{REFERÊNCIAS}

Antipoff, C. A. (2010). Uma proposta original na educação de bem-dotados: ADAV-Associação Milton Campos para desenvolvimento e assistência de vocaçóes de bem dotados em sua primeira década de funcionamento: 1973 - 1983 [Dissertação de Mestrado, Faculdade de Educação da Universidade Federal de Minas Gerais]. Repositório da UFMG. https://repositorio.ufmg.br/bitstream/1843/ BUOS-8CJMX4/1/disserta_o___pdf__vers_o_final.pdf

Araújo Á. C., \& Lotufo Neto, F. (2014). A nova classificação americana para os transtornos mentais - o DSM-5. Revista Brasileira de Terapia Comportamental e Cognitiva, XVI(1), 67-82.

Bentes, J. A. de O. (2010). Formas do trabalho docente na educação de surdos [Tese de Doutorado, Universidade Federal de São Carlos]. Repositório da UFSCar. https://repositorio.ufscar.br/ bitstream/handle/ufscar/2868/3215.pdf?sequence=1

Bentes, J. A. de O., \& Hayashi, M. C. P. I. (2016). Normalidade, diversidade e alteridade na história do instituto nacional de surdos. Revista Brasileira de Educação, 21(67), 851-874. https://doi. org/10.1590/S1413-24782016216744

Brito, F. B. (2016). O Movimento Surdo no Brasil: a busca por direitos. Journal of Research in Special Educational Needs, 16, 766-769. https://doi.org/10.1111/1471-3802.12214

Bueno, J. G. S. (2011). Educaçâo especial brasileira: questóes conceituais e de atualidade. Educ.

Cabral Filho, A. V., \& Ferreira, G. (2013). Movimentos Sociais e o Protagonismo das Pessoas com Deficiência. SER Social, 15(32), 93-116. https://doi.org/10.26512/ser_social.v15i32.13036

Decreto no 5.626, de 22 de dezembro de 2005. Regulamenta a Lei n. ${ }^{\circ} 10.436$, de 24 de abril de 2002, que dispóe sobre a Língua Brasileira de Sinais - LIBRAS, e o art. 18 da Lei n. ${ }^{\circ} 10.098$, de 19 de dezembro de 2000. http://www.planalto.gov.br/ccivil_03/_ato2004-2006/2005/decreto/d5626.htm

Decreto no 9.198 de 12 de dezembro de 1911. Aprova o regulamento para o Instituto Nacional de Surdos-Mudos. https://bit.ly/2UHToJr

Decreto no 9.665, de 2 de janeiro de 2019. Aprova a Estrutura Regimental e o Quadro Demonstrativo dos Cargos em Comissão e das Funçôes de Confiança do Ministério da Educação, remaneja cargos em comissão e funçốes de confiança e transforma cargos em comissão do Grupo-Direção e Assessoramento Superiores - DAS e Funçôes Comissionadas do Poder Executivo - FCPE. http:// www.planalto.gov.br/ccivil_03/_Ato2019-2022/2019/Decreto/D9665.htm

Decreto no 24.794, de 14 de julho de 1934. Cria, no Ministério da Educação e Saúde Pública, sem aumento de despesa, a Inspetoria Geral do Ensino Emendativo, dispóe sôbre o Ensino do Canto Orfeônico, e dá outras providências. https://bit.ly/32LPxj2

Decreto no 72.425, de 3 de julho de 1973. Cria o Centro Nacional de Educação Especial (CENESP), e dá outras providências. https://www2.camara.leg.br/legin/fed/decret/1970-1979/decreto-724253-julho-1973-420888-publicacaooriginal-1-pe.html 
Evangelista, O. (2012). Apontamentos para o trabalho com documentos de política educacional. In R. M. L. Araujo, \& D. S. Rodrigues (Orgs.), A pesquisa em trabalho, educação e políticas educacionais (1 $1^{\text {a }}$ ed., pp. 52-71). Alínea.

Federação Nacional de Educação e Integração dos Surdos (1993). As comunidades surdas reivindicam seus direitos linguisticos. FENEIS.

Garcia, R. M. C. (2017). Disputas conservadoras na política de educação especial na perspectiva inclusiva. In R. M. C. Garcia (Org.), Políticas de educação especial no Brasil no início do século XXI (1 $1^{\text {a }}$ ed., pp. 19-66). Núcleo de Publicaçóes do CED - NUP.

Gramsci, A. (1976). Maquiavel, a política e o Estado moderno. Civilização Brasileira.

Guenther, Z. C. (2007). CEDET - Um programa de sucesso na educação de dotados e talentosos. Psicologia em Pesquisa, 1(02), 96-106.

Guenther, Z. C. (2013). Editorial: Quatro lustros de lembranças... Informativo ASPAT-CEDET, 4. http://nemeth-torres.blogspot.com/2017/08/informativo-aspat-cedet-n-4-20122013.html

Guenther, Z. C., \& Rondini, C. A. (2012). Capacidade, dotação, talento, habilidades: uma sondagem da conceituação pelo ideário dos educadores. Educação em Revista, 28(1), 237-266.

Jannuzzi, G. S. de M. (2012). A educação do deficiente no Brasil: dos primórdios ao início do século XXI. Autores Associados.

Kassar, M. C. M. (1998). Liberalismo, neoliberalismo e educação especial: algumas implicações. Cadernos CEDES, 19(46), 16-28. http://doi.org/10.1590/S0101-32621998000300003

Lacerda, C. B. F. (1998). Um pouco da história das diferentes abordagens na educação dos surdos. Caderno Cedes, 19(46), 68-80. http://doi.org/10.1590/S0101-32621998000300007

Lanna Júnior, M. C. M. (2010). História do movimento político das pessoas com deficiência no Brasil. Secretaria de Direitos Humanos/Secretaria Nacional de Promoção dos Direitos da Pessoa com Deficiência.

Lehmkuhl, M. S. (2018). A reconfiguração da Federação Nacional das APAES (FENAPAES) no estabelecimento da relação entre público e o privado nas políticas de educação especial - 1974- 2016 [Tese Doutorado, Pontifícia Universidade Católica de São Paulo]. Biblioteca Digital da PUC-SP. https://tede2.pucsp.br/handle/handle/21158

Lei no 4.024, de 20 de dezembro de 1961. Fixa as Diretrizes e Bases da Educação Nacional. https://www. planalto.gov.br/ccivil_03/Leis/L4024.htm

Lei no 5.692, de 11 de agosto de 1971. Fixa Diretrizes e Bases para o ensino de $1^{\circ}$ e $2^{\circ}$ graus, e dá outras providências. https://bit.ly/3f3bgrA

Lei no 10.436, de 24 de abril de 2002. Dispóe sobre a Língua Brasileira de Sinais - LIBRAS e dá outras providências. http://www.planalto.gov.br/ccivil_03/leis/2002/110436.htm

Lei no 12.764, de 27 de dezembro de 2012. Institui a Política Nacional de Proteçáo dos Direitos da Pessoa com Transtorno do Espectro Autista; e altera o $\$ 3^{\circ}$ do art. 98 da Lei n. ${ }^{\circ} 8.112$, de 11 de dezembro de 1990. http://www.planalto.gov.br/ccivil_03/_ato2011-2014/2012/lei/112764.htm

Lei $\mathrm{n}^{\circ}$ 13.146, de 6 de julho de 2015. Institui a Lei Brasileira de Inclusão da Pessoa com Deficiência (Estatuto da Pessoa com Deficiência). http://www.planalto.gov.br/ccivil_03/_ato2015-2018/2015/ lei/l13146.htm

Lemos, E. R. (1981). A educação de excepcionais: evolução histórica e desenvolvimento no Brasil [Tese de Livre-Docência não publicada]. Universidade Federal Fluminense. 
Mendonça, S. R. de. (2014). O Estado ampliado como ferramenta metodológica. Marx e o Marxismo, 2(2), 27-43.

Montaño, C., \& Duriguetto, M. L. (2011). Estado, classe e movimento social. Cortez.

Nowill, D. (2009). 62 anos de inclusão do deficiente visual. Comunicação \& Educação, 14(1), 99-106. https://doi.org/10.11606/issn.2316-9125.v14i1p99-106

Parecer CNE/CEB no 17, de 3 de julho de 2001. Diretrizes Nacionais para a Educaçáo Especial na Educação Básica. http://portal.mec.gov.br/cne/arquivos/pdf/CEB017_2001.pdf

Pérez, S. G. P. B. (2012). E que nome daremos à criança. In L. C. Moreira, \& T. Stoltz (Eds.), Altas Habilidades/ Superdotação, Talento, Dotação e Educação (1 a ed., p. 45-62). Juruá.

Política Nacional de Educação Especial (1994). MEC/SEESP. https://inclusaoja.files.wordpress. com/2019/09/polc3adtica-nacional-de-educacao-especial-1994.pdf

Política Nacional de Educação Especial na Perspectiva da Educação Inclusiva (2008). MEC/SECADI. http:// portal.mec.gov.br/index.php?option=com_docman\&view=download\&alias=16690-politicanacional-de-educacao-especial-na-perspectiva-da-educacao-inclusiva-05122014\&Itemid=30192

Política Nacional de Educação Especial: equitativa, inclusiva e ao longo da vida (2018) Secadi/MEC. https://pnee.mec.gov.br/integra

Rafante, H. C. (2011). Helena Antipoff, as sociedades Pestalozzi e a Educação Especial no Brasil [Tese Doutorado, Centro de Educação e Ciência Humanas, Universidade Federal de São Carlos]. Repositório Institucional UFSCar. https://repositorio.ufscar.br/bitstream/handle/ufscar/2261/ TeseHCR.pdf?sequence $=1$ \&isAllowed $=\mathrm{y}$

Rafante, H. C. (2015). Política de educação especial no Brasil: a relação entre o estado, a sociedade civil $e$ as agências internacionais na criação do CENESP [Apresentação de artigo]. 37a Reunião Anual da ANPEd, Florianópolis, Santa Catarina, Brasil. https://anped.org.br/sites/default/files/trabalhogt15-3916.pdf

Rafante, H. C., \& Lopes, R. E. (2009). Helena Antipoff e a educação dos “excepcionais": uma análise do trabalho como princípio educativo. Revista HISTEDBR On-line, 33, 228-252. https://doi. org/10.20396/rho.v9i33.8639565

Resolução no 2, de 11 de setembro de 2001. Institui as Diretrizes Nacionais para a Educação Especial na Educação Básica. http://portal.mec.gov.br/cne/arquivos/pdf/CEB0201.pdf

Rios, C. (2017). "Nada sobre nós, sem nós"? O corpo na construção do autista como sujeito social e político. Sexualidad, Salud y Sociedad, 25, 212-230. https://doi.org/10.1590/1984-6487. sess.2017.25.11.a

Shiroma, E. O., \& Evangelista, O. (2018). Subsídios teórico-metodológicos para o trabalho com documentos de política educacional: contribuiçôes do marxismo. L. Gonçalves (Org.), Trabalho e Educação: interlocuçóes marxistas (1ª ed., pp. 87-124). Editoria da FURG.

Silva, J. H. (2017). Federação Nacional das APAEs no Brasil: hegemonia e propostas eduacionais (19902015) [Tese Doutorado, Universidade Federal de São Carlos]. Repositório BDTD/IBICIT da UFSCar. https://bdtd.ibict.br/vufind/Record/SCAR_361bbc5ef17ad92f539ff42a4953ff35

Recebido em: 04/11/2019

Reformulado em: 31/03/2020

Aprovado em: 07/04/2020 